\title{
Spiral Pitch
}

National Cancer Institute

\section{Source}

National Cancer Institute. Spiral Pitch. NCI Thesaurus. Code C151972.

The distance between sucessive turns of a spiral helix. 